\title{
ZT-40 Administrative Plan
}

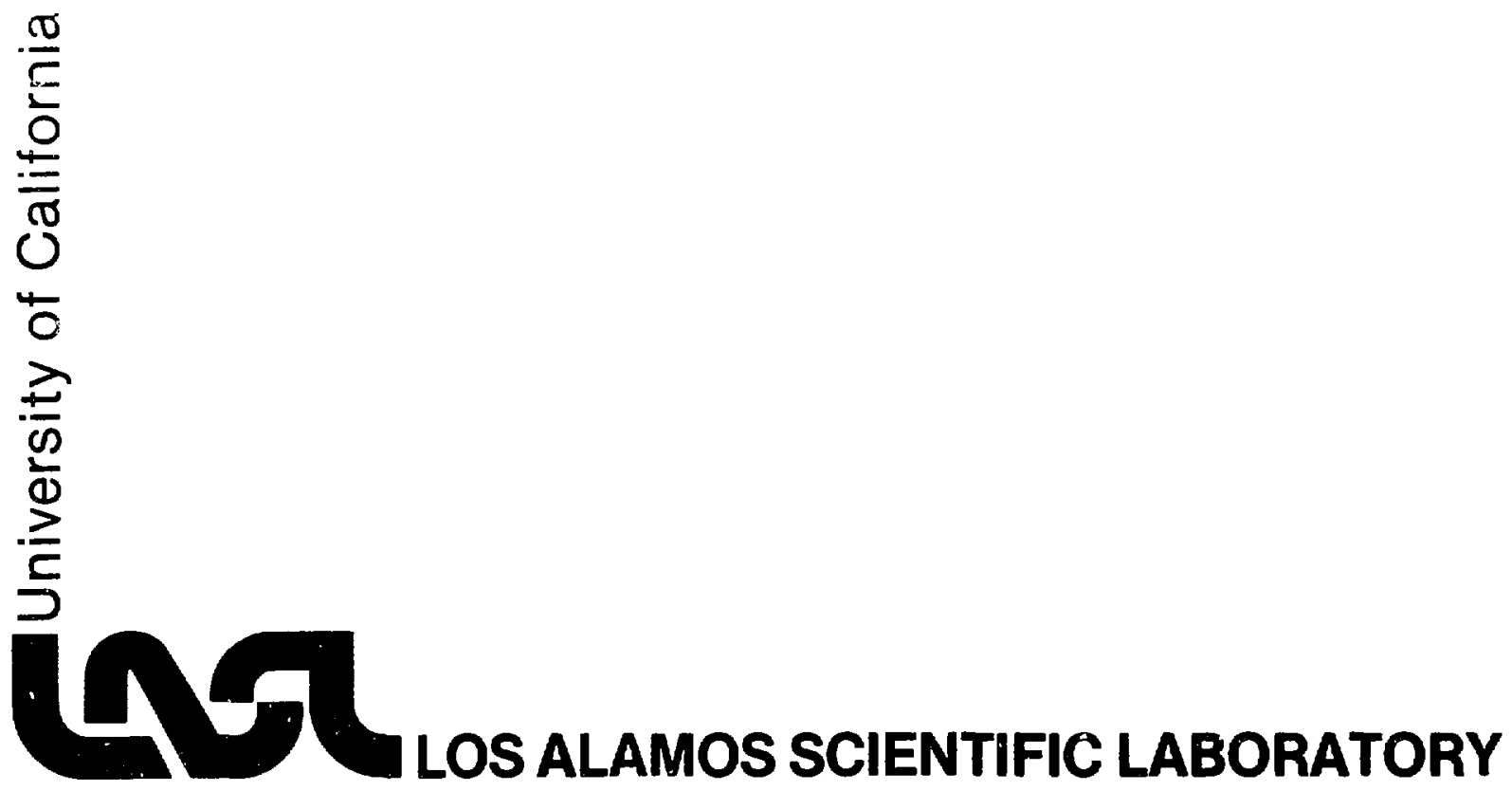


LA-7425-MS

Informal Report

Special Distribution

Issued: August 1978

\title{
ZT-40 Administrative Plan
}

\author{
Compiled by
}

K. S. Thomas

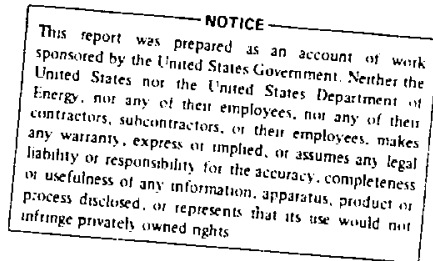



developed. It describes baselines and procedures that will be used for the remainder of the construction phase of the project.

\section{OBJECTIVES OF ADMINISTRATIVE PLAN}

The 2T-40 project was proposed in March 1976, and began in January 1977, without a formal administrative plan. The following $\mathrm{plan}$ is being implemented after the project is well under way, and therefore, certain of the procedures will reflect this situation.

Beginning on September 1, 1977, progress on the $2 T-40$ project has been reported to DOE by means of a series of bimonthly progress reports. The reporting procedure will continue under this plan. (Completed milestones for the $2 T-40$ project are given in Table 4.)

Two areas of concern remain that may affect the $2 T-40$ project. First, the funding for the power crowbar switch development, which is essential for the 2T-40 device, is uncertain since OFE's Development and Technology office has reduced LASL's FY-79 budget to zero in the area of component development. Secondly, in order to minimize sources of impurities a homogeneous vacuum torus without 0 -ring seals may be required. This is a 1 ong-lead item that will require development work and presently is not included in the $2 T-40$ funding. In addition a thin metallic vacuum liner may be needed for the slower methods of setting up the RFP configurations.

This plan describes the Los Alamos Scientific Laboratory (LASL) procedures that will be used to guide and monitor the remainder of the $2 T-40$ project. 
The plan identifies the reporting and review procedures for the project; establishes technical, cost, and schedule baselines; and specifies a system for effecting changes to the established baselines. organizational relationships between LASL project management and OFE are identified.

Baselines and procedures described in the plan will be used by DOE co monitor progress of the project and to recognize potential problems so that timely actions can minimize their effects on the project's efficient and economical completion.

\section{ZT-40 PROJECT OBJECTIVES AND TECHNICAL BASELINES}

\section{1 Project Physics Parameters (Leve1 1)}

With the earlier experiments at LASL, ZT-1, and $2 \mathrm{~T}-\mathrm{S}$ as a guideline, the 2T-40 experiment has been designed to allow a decisive test of the Reversed-Field Pinch concept. This test consists of an evaluation of the following aspects of the concept.

- Equilibrium: The field and pressure profiles required for equilibrium in the large-scale toroidal geometry of ZT-40 will be studied.

- Stability: The stability of the reversed-field configuration will be determined as a function of critical parameters such as current, plasma density, beta, and time scale. Stability also will be tested for its sensitivity to profile variations, which can be built in with different programing techniques.

- Transport: The transport properties of the stable discharges in $2 \mathrm{~T}-40$ will be investigated.

- Heating: The RFP confinement system has the potential of ohmic heating to ignition with relatively low magnetic fields. The goal in ZT-40 is to explore the limits of the current densities that can be achieved without introducing excessive transport.

- Impurities: A major goal of $2 T-40$ is to achieve a sufficiently low impurity level to allow the plasma to overcome the radiation barrier and reach temperatures in excess of $\sim 100 \mathrm{eV}$. 
These studies are to be carried out with the fast setting-up method first. The parameters for this method are given in Table 1. The slow "self-reversal" method is to be studied next.

The initial experiments with a 12-feedpoint design will have a current rise of $\sim 2.5 \mu s$ and will be performed with a passive crowbar that has a current decay time of $\sim 100 \mu \mathrm{s}$, which will limit the plasma lifetime. The power crowbar, which will be added later, will maintain the current nearly constant for $\sim 200$ ts with a subsequent decay time of approximately 1 ms. A singlecurrent feedpoint design will have a risetime of $20 \mu \mathrm{s}$ and maintain the current nearly constant for $\sim 2$ ms. A slow self-reversal mode can be achieved with the single-feedpoint arrangement by driving with the power crowbar banks. In addition, by eliminating the single feedpoint and inducing the plasma current with a multi-turn primary, all the controiled programmed modes can be studied with slower current risetimes.

\subsection{ZT-40 Engineering Parameters (Leve1 2)}

Based on the engineering description given in the $2 T-40$ proposal (LA-6625-P), those sngineering parameters required to define a Level 2 baseline for the project are listed here by subsystem.

TABLE 1

PARAMETERS FOR PROGRAMMED NPERATIONS

\section{Machine}

Torus major radius

Discharge tube inner radius

Aluminum shell inner radius

Number of feed points - Primary $\phi$-current

Number of turns - $\theta$-coil
Value

$114.3 \mathrm{cw}$

$20.0 \mathrm{~cm}$

$22.0 \mathrm{~cm}$

$1-12$

$1-20$

Expected plasma parameters

Central plasma density

$\sim 5 \times 10^{15} \mathrm{~cm}^{-3}$

Plasma temperature

$100-200 \mathrm{eV}$

Toroidal plasma current

$<600 \mathrm{kA}$

Stable plasma lifetime

$\geq 200 \mu \mathrm{s}$ 


\subsection{Structural System}

The structural system includes the machine support, the various platforms around the machine, and the capacitor racks. The machine support is an aluminum weldment to avoid magnetic effects, whereas the other platforms and racks are structural steel.

\subsection{Energy Storage Capacitors}

The energy storage system consists of four capacitor banks; a 1.5-MJ, 10-kV bias bank; a $0.25-\mathrm{MJ}$ preionization bank; a $0.6-\mathrm{MJ}, 50-\mathrm{kV} \mathrm{I}_{\phi}$ bank, and a $0.6-\mathrm{MJ}, 50-\mathrm{kV} \mathrm{I}$ reversing bank. Two $2-\mathrm{MJ}, 10-\mathrm{kV}$ capacitor banks are used to power crowbar the $I_{\phi}$ bank and the $I_{\theta}$ reversing bank.

2.221 Capacitors. Generally speaking, two types of capacitors are used, $1.85-\mu F, 60-k V$ Scyllac-type capacitors, and $170-\mu \mathrm{F}, 10-\mathrm{kV}$ high-energy density capacitors. About 600 of the $60-\mathrm{kV}$ units and about 650 of the lower voltage units are required.

\subsection{Switches}

Each high-voltage capacitor has a pressurized field-distortion spark gap mounted on it. The low-voltage bank 1s switched with size $D$ ignitrons. In addition there are 288 Scyllac-type crowbar spark gaps to crowbar the two high-voltage banks. For power crowbar operation these switches will be replaced by a new high-coulomb switch to be developed at the LASL.

\subsection{Charging System}

The charging system includes constant-current regulating devices, power supplies, charging resistors, and shorting switches to insure the safety of the system.

\subsection{Triggering System}

The high-voltage spark gaps are triggered by the circuit developed for Scyllac using improved triggering spark saps. The ignitrons use a conventional ignitron triggering system.

\subsection{Transmission System}

2.261 Cables. Coaxial cables are used to conduct the current from the capacitors to the experiment. These cables are the same (RG 17/14) type that are used in Scyllac. 
2.262 Current Mixer. A low-inductance aluminum ring assembly is used to equalize the currents from each high-voltage bank in the event of a malfunction among any of the spark gaps in the bank. Two assemblies are required, one for the $I_{\phi}$ current and one for the $I_{\theta}$ current.

2.263 Iron Cora. Twelve iron cores are used around the machine primary to increase the coupling from the $I_{\phi}$ bank to the plasma.

\subsection{Control System}

The entire experiment is controlled by a Prime 400 computer that is interfaced with a CAMAC system. Fiber-optics are used for all signa! transmissions to minimize EM noise problems. The computer and interface system are housed in a shielded room adjacent to the experiment.

\subsection{Machine Components}

The machine is defined as the $I_{\phi}$ header, the primary shell, and the vacuum torus.

2.281 Header and Primary shel1. The $\mathrm{I}_{\phi}$ header is an aluminum assembly designed to minimize internal field perturbations. The assembly is potted in epoxy to accomodate the high voltage from the capacitor bank cables. Twelve headers are required, each header being attached to sections of the primary shell, which induces the $I_{\phi}$ current into the plasma.

2.282 Torus. The vacuum torus is made of high-purity alumina rings that are glazed into toroidal sectors with a high-temperature glazing material. The sectors are joined together using a minimum of $0-r i n g s$. Some sectors have speciai ports for vacuum pump-out and diagnostics. In order to minimize sources of impurities a homogeneous vacuum torus without 0 -ring seals may be required. A thin metallic vacuum liner may be needed for the slower methods of setting up the RFP configurations.

\subsection{Vacuum System}

The vacuum system is designed to produce a vacuum in the torus in the $10^{-8}$ torr range. There are four pump stations around the torus. The system includes appropriate valves, two oil-iree turbo pumps, two lHe cryc-pumps and two titanium ion pumps. A Roots blower nechanical pump assembly is used for soughing the system. The vacuum system is computer concrolled with appropriate logic to insure reliable operation. 


\subsection{Diagnostics System}

The diagnostics for the ZT-40 experiment will provide the following measurements: plasma density with Thomson scattering, multichannel and scanning interferometers; plasma temperature by one- and two-dimensional Thomson scattering and spectroscopy; magnetic fields with Faraday rotation, magnetic and wave probes; impurities by spectroscopy and mass analyzers; and gross plasma instability with streak cameras and exterior Fourier magnetic probes.

\subsection{Power Crowbar System}

The function of the power crowbar (PCB) system is to maintain the $I_{\phi}$ and $I_{\theta}$ currents constant within $7 \%$ for 200 is after crowbarring. These currents will be maintained for millisecond timescales. Power crowbarring is accomplished by adding energy from a $10-\mathrm{kV}$ capacitor bank via low-loss transformers to the $I_{\phi}$ and $I_{\theta}$ circuits.

2.311 Capacitors and Ignitrons. About 4 MJ of 10-kV, high-density capacitors are required for the PCB system. These capacitors are switched and crowbarred by size $\mathrm{D}$ ignitrons.

2.312 Transformers. Twelve low leakage inductance transformers are required for each of the $I_{\phi}$ and $I_{\theta} P C B$ circuits. These transformers are being developed using a concept that originated in Japan. Special iron cores are required as well as a unique system of transformer windings.

2.313 Crowbar switches. The crowbar switches originally being installed in $2 T-40$ are rated at 15 coulombs each, which is adequate for the passive crowbar case. When the power crowbar system is installed the crowbar switches must conduct at least 25 coulombs each. Although the original switches may survive, their life and reliability are very doubtful. New high-coulomb switch designs are being developed and a new PCB switch design will ultimately be installed for crowbarring the system.

\subsection{Electrical Prototype}

An electrical prototype of one-twelfth of one of the two high-voltage banks has been built. It has been used to determine trigger system performance, to examine available operating ranges, and to conduct tests to determine how well electrical transients can be suppressed using RLC shunts across the mixers. Later the prototype w111 be used to test power crowbar components . 


\section{ORGANIZATION AND LASL MANAGEMENT PROCEDURES}

\section{1 Organization}

Figure 1 shows the organization chart of that part of the LASL CTR Division that is relevant to the $2 \mathrm{~T}-40$ project. The physics and engineering groups function witnin the general CTR Division matrix organization. The steering committee is responsible for the physics requirements and for int grating them into the system design. This comittee also makes major decisions on design, schedules, and procurement. The construction manager is responsible for the design, procurement, and construction of the entire project. The design and integration of each subsystem is led by a designated responsible engineer.

Physicists are responsible for establishing the design criteria, for relating the physics objectives to the engineering designs, for the final approval of designs, and for planning the physics program.

Procurement services are provided by the LASL Supply and Property Department. After appropriate CTR Division approval is obtained, purchase requests are forwarded to the SP Department for procurement. A designated person on the $\mathrm{ZT}-40$ team follows all procurements and keeps the requesting engineer aware of the status of each order.

The safety aspects of each design are specifically discussed during the design review process. Hazards are identified and noted in design review minutes and appropriate action is taken to accommodate the particular problem. These actions are also do umented in minutes of meetings.

The project interface with DOE will occur through the Alternate Concepts Branch of OFE. Figure 2 shows the relevant organization chart for OFE. The primary liaison for project monitoring will be between the LASL construction manager and the DOE project contact identified in Fig. 2.

OFE has responsibility for the DOE technical management of the project and for approving the project objectives. I" is further responsible for the necessary funding for the accomplishment of the project.

LASL is responsible for project design and execution, as authorized withIn approved cost and schedule guidelines. It is also responsible for the management of the project activities within the framework of this administrative plan. 


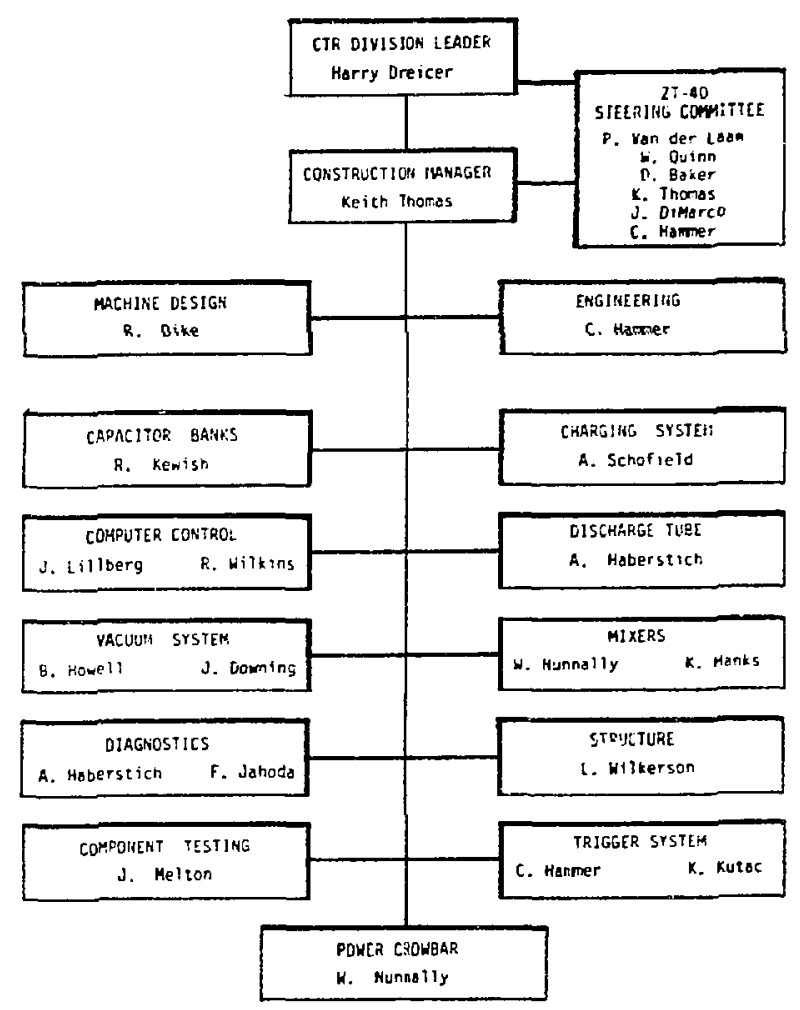

Fig. 1. CTR Division organization chart for $2 \mathrm{~T}-40$ project.

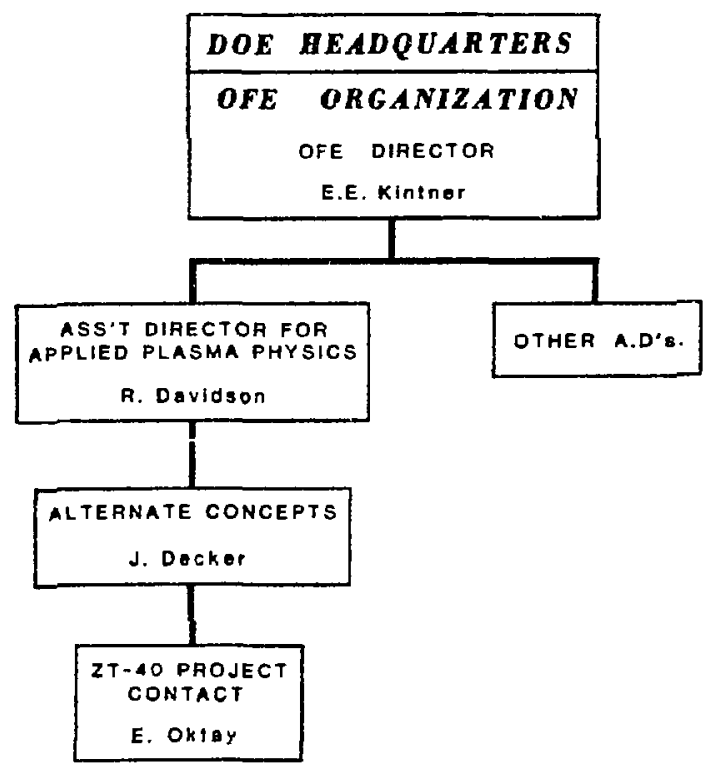

Fig. 2. Organization chart for US Department of Energy, Office of Fusion Energy. 


\subsection{LASL Management Procedures}

\subsection{Design Meetings}

Design meetirigs are held on a regular basis to initiate and monitor each design. The purpose of these meetings is to obtain comment and approval of each design. Official minutes of these meetings are issued recording the comments and decisions made. Participants will include ail mechanical and electrical designers and physics personnel concerned affected by the design.

\subsection{2}

Construction Meetings

Construction staff meetings are held at approximately weekly intervals. The purpose of these meetings is to discuss the progress of the construction, plan the activities for the next interval, and identify any design, procurement, or personnel problems that affect construction.

\subsection{Highlights Meetings}

Highlights meetings are held at approximately monihly intervals. These meetings are attended by all the design engineers and the physicists responsible for the project and minutes of the proceedings are issued. The purpose of these meetings is to:

- Inform all personnel of the general status of the project,

- Discuss the immediate schedule and objectives,

- Identify design, procurement, or construction problems,

- Inform the personnel of any new physics or other objectives.

$3.24 \quad$ Project Sumnary Network

LASL has established a project summary networls involving a simple PERT diagram and a bar chart, which is attached in the appendix. The network is used to identify the principal activities of the project and monitor the progress of each activity. The critical path of the project has been identified by the use of the PERT chart. This network will be updated by the construction manager at least every four months.

\subsection{Work Breakdown Structure}

A work breakdown structure (WBS) has been made for the project identifying the principal design and development activities, and the estimated personnel requirements. The WBS was used to organize the design and development work-task assignments. 


\section{REPORTING AND REVIEW PROCEDURES}

\subsection{Bimonthly Progress Reports}

A progress report will be submitted to OFE by the 20 th of each alternate month and will consist of the following:

- Presentation in tabular form of costs by subsystem for the current fiscal year and for the project total. Listings will include the current approved baseline and commitments to date.

- A narrative discussion as necessary to clarify the table, and to relate progress to the milestones and project schedule.

\subsection{Six-Month Reviews}

There will be joint project reviews by OFE and LASL during the months of October 1978, April 1979, and October 1979. These reviews will include a witten report and an oral presentation by LASL for:

- $\quad$ ?hnical update

- cost status and projection

- schedule review and projection.

\subsection{Telephone Communications}

There will be telephone communication between the construction manager and $O F E$ on alternate weeks and at other times as needed.

\subsection{Special Reviews}

There may be unscheduled reviews by OFE for particular problews that need resolution. These reviews may be called by OFE or LASL as required. At least one week notice must be given to all participants.

\section{BASELINE DEFINITICE .ND CHANGE MECHANISMS}

Baselines for technical, cost, and schedule control are defined and mechanisms for baseline changes are specified with required approval levels. 


\subsection{Technical Baselines}

The technical baselines are those identified in Sections 2.1 (Leve1 1) and 2.2 (Level 2) of this plan or its approved revisions.

5.11

Changes for Level 1

Changes to Level 1 baselines (Section 2.1), shall be submitted by LASL to OFE when a change is indicated as a result of physics requirements. The proposed change shall identify the reasons, provide LASL's technical arguments, and be accompanied by LASL's assessment of impact on the cost and schedule of baselines.

- Evaluation - OFE evaluates the technical merits of the
change and balances the programmatic advantages vs the
cost-schedule impact.
Approval - OFE issues approval to LASL.
5.12 Changes for Level 2 (Significant Change)
Changes to Level 2 technical baselines as detailed in Section 2.2 shall be submitted by LASL to OFE, when a significant change is indicated. A significant change is defined as a deviation fron the approved Level 2 technical baselines that affects the cost and/or schedule baselines as discussed in Sections 5.2 (changes in excess of $\$ 100,000$ ) and 5.3 (schedule delay of two months or more for completion).

- Reviews - OFE evaluates the technical merits, the cost and schedule perspective, and consults with LASL.

- Approval - OFE issues approval to LASL.

5.13 Changes to Level 2 (Changes Below Approval Leve1)

Changes to the Level 2 technical baselines that do not qualify as significant changes (Section 5.12) will be approved by the zT-40 construction manager and be recorded. LASL will maintain a current set of Level 2 technical baselines and will issue any revisions at the time of the six-month reviews.

\subsection{Cost Baseline}

Table 2 shows the materials and contract labor cost baseline estimates, and Table 3 shows cost baseline sumary. These are April 1978 estimates. 
5.21 Changes up to $\$ 100,000$ (Above Total Estimated Cost Without

\section{Contingencies)}

The LASL construction manager is authorized to approve cost changes up to $\$ 100,000$. Written dccumentation of a11 cost changes over $\$ 10,000$ shall be kept in the LASL project files. The approved changes sha11 be reflected in the bimonthly cost report. Any cost change that causes the project to exceed the project's total estimatad cost (TEC) shall require written approval by OFE. Changes in Excess of $\$ 100,000$.

All cost changes in excess of $\$ 100,000$ sha11 require written approval of OFE.

\subsection{Schedule Baseline}

LASL has used a simple PERT network to identify the milestones shown in Table 4. This table forms the schedule baseline for the ZT-40 project. Any slip in the milestones that may delay the completion date of the project by two months or more will constitute a baseline change.

\section{DEFINITION OF END OF MAJOR DEVICE FABRICATION}

The ZT-40 project will be considered completed as far as the approved MDF funding is concerned when $O F E$ is satisfied through performance tests and an overall assessment that the project can meet the authorized Level 1 objectives as amended, and that operability and safety criteria are satisfied. Specifically, the construction project will be considered to be completed when the following criteria are met.

1. All necessary subsystem elements are in place and operable, and LASL safety requirements are satisfied.

2. Technically, there is a high level of confidence that the configured system can perform at the level anticipated in the project authorization and achieve the physics parameters of Table 1 . 
TABLE 2

COST BASELINES

Materlals Cost Baseline

\begin{tabular}{|c|c|c|c|c|c|}
\hline Capacitors & $\$ 154 R$ & $\$ 39 K$ & $\$ 26 \mathrm{R}$ & - & $\$ 219 \mathrm{~K}$ \\
\hline Cable Syatem & - & - & 116 & 10 & 126 \\
\hline Structural & & 114 & 20 & - & 134 \\
\hline Iros Core & & 151 & 99 & - & 250 \\
\hline Machine Components & & 91 & & & 91 \\
\hline Mixer & & & 140 & 30 & 170 \\
\hline Primary \& Feedplates & & & 91 & 120 & 211 \\
\hline Charging System & & 84 & 35 & - & 119 \\
\hline Trigger System & & 119 & 23 & - & 142 \\
\hline Switches & & 257 & 34 & - & 291 \\
\hline Control System & & 74 & 100 & - & 174 \\
\hline Ceremic Torus & & & 171 & - & 171 \\
\hline Vacuum System & & 55 & 60 & - & 115 \\
\hline Ait System & & & 15 & & 15 \\
\hline Diagnostics & & & 25 & & 25 \\
\hline Mi sc. Hardware & $\longrightarrow$ & 45 & - & - & 45 \\
\hline Subtotalo & $\$ 154 R$ & $\$ 1029 \mathrm{R}$ & $\$ 955 K$ & $\$ 160 \mathrm{R}$ & $2298 \mathrm{x}$ \\
\hline \multicolumn{6}{|l|}{ PowerCrowbar } \\
\hline Switches & & & & $\$ 190 \mathrm{~K}$ & $\$ 190 \mathrm{~K}$ \\
\hline Capacitors & & & 90 & & 90 \\
\hline Trans former & & & 25 & 390 & 415 \\
\hline \multirow[t]{2}{*}{ Hardware } & & & - & 160 & 160 \\
\hline & & & $\$ 115 \mathrm{R}$ & $\$ 740 \mathrm{~K}$ & $\$ 855 \mathrm{~K}$ \\
\hline IOTALS & \$I 54R & $\$ 1029 \mathrm{R}$ & \$1070R & $\$ 900 R$ & $\$ 3153 \mathrm{~K}$ \\
\hline
\end{tabular}

Contract Lsbor Cost Baseline

$\begin{array}{lcccc}\text { Contract Engineering } & \frac{\text { FY 77 }}{\$ 13 \pi} & \frac{\text { FY 78 }}{\$ 9 R} & \frac{\text { FY 79 }}{\text { Total }} \\ \text { Zia Crafts } & \$ 77 & 198 & \frac{22 \mathrm{R}}{\$ 27} \\ \text { Temporary Technicians } & \frac{107}{\$ 187 \mathrm{~K}} & \frac{227}{\$ 434 \mathrm{R}} & & \frac{334}{\$ 621 \mathrm{~K}}\end{array}$


TABLE 3

COST BASELINE SUMMARY

$\underline{F T-76} \underline{\text { FY-77 }} \underline{\text { FY-78 }} \underline{\text { FY-79 }}$ Total

MDF

\$154K \$2386K $\quad \$ 3429 \mathrm{~K} \quad \$ 2095 \mathrm{~K} \quad$ \$8064K

A) Procurement

$\$ 154 \mathrm{~K} \quad \$ 1216 \mathrm{~K} \quad \$ 1504 \mathrm{~K} \quad \$ 900 \mathrm{~K} \quad \$ 3774 \mathrm{~K}$

Material

154

1029

1070

900

3153

Contract, 1abor \& eng.

434

0

621

B) LASL Operation

$\$ 805 \mathrm{~K}$

$\$ 1609 \mathrm{~K}$

$\$ 1025 \mathrm{~K}$

$\$ 3439 \mathrm{~K}$

Design

Assembly

Fabrication

Administration

Subtotal $(A+B)$

$\$ 154$

$\$ 2021$

$\$ 3113$

$\$ 1925$

$\$ 7213$

C) Capital Equipment

$\$ 365 \mathrm{~K} \quad \$ 316 \mathrm{~K} \quad \$ 170 \mathrm{~K}$

$\$ 851 \mathrm{~K}$ 
TABLE 4

ZT-40 MILESTONES

Completed Milestones

$\begin{array}{llll}\text { Letter of Intent } & \text { March } & 1976 & \text { Complete } \\ \text { Conceptual Design Began } & \text { March } & 1976 & \text { Complete } \\ \text { Proposal Reviewed } & \text { August } & 1976 & \text { Complete } \\ \text { Cleared Experimental Area } & \text { April } & 1977 & \text { Complete } \\ \text { Begin Installation of Structure } & \text { June } & 1977 & \text { Complete } \\ \text { Begin Installation of Energy System } & \text { August } & 1977 & \text { Complete } \\ \text { Structure Installation Complete } & \text { August } & 1977 & \text { Complete } \\ \text { Delivery of Computer } & \text { September } & 1977 & \text { Complete } \\ \text { Complete Construction of Electrical Prototype } & \text { November } & 1977 & \text { Complete } \\ \text { Complete Installation of New Crane } & \text { February } & 1978 & \text { Complete } \\ \text { Installation of First Mixer } & \text { February } & 1978 & \text { Complete } \\ \text { Complete Checkout of Electrical Prototype } & \text { March } & 1978 & \text { Complete }\end{array}$

\section{Remaining Milestones}

Complete Installation and Checkout of Computer June $\quad 1978$

Complete Installation of Mixers

July 1978

Complete Installation of Energy System

September 1978

Begin Checkout of Control System

October $\quad 1978$

Begin Checkout of Energy Syster

October $\quad 1978$

Complete Procurement of Metal Primary

January 1979

Installation of Ceramic Torus

Apri1 1979

Complete Installation of Vacuum System June 1979

Complete Installation of Machine Components July 1979

$\begin{array}{lll}\text { Initial Plasma Studies September } & 1979\end{array}$

$\begin{array}{lll}\text { Begin Installation of Power Crowbar System } & \text { October }\end{array}$

Complete Power Crowbar Installation $\quad 1980$

$\begin{array}{lll}\text { Start Plasma Studies with Power Crowbar July } & 1980\end{array}$ 


\section{CHANGE PROCEDURES FOR ADMINISTRATIVE PIAN}

Revisions and/or changes to the Administrative Plan may be initiated by OFE or by LASL, when sufficient cause exists. Revision and/or changes to the administrative plan will require approval of both participants with one exception: OFE recerves the right to change baseline approval levels, contingency management level, or subsystem (vs total project) cost control if, in $O F E$ 's judgment, project performance warrants the change. Final implementation of any revisions and/or changes will be communicated formally to LASL by OFE.

8. APPROVAL OF ADMINISTRATIVE PLAN

This plan is adopted and approved and will remain in effect until the completion of the $2 T-40$ project, subject to changes that may occur by the procedure of Section 7 .

E. Oktay, ZT-40 Project Contact Alternate Concepts Branch, OFE

K. S. Thomas

2T-40 Construction Manager, LASL 


\section{APPENDIX}

ZT-40 PROJECT PRINCIPAL ACTIVITIES

Bar charts showing schedules for principal activities of the $2 \mathrm{~T}-40$ project are presented in this Appendix. The charts show the periods of design and development (D), procurement ( $P$ ), installation ( $I)$, and checkout (C).

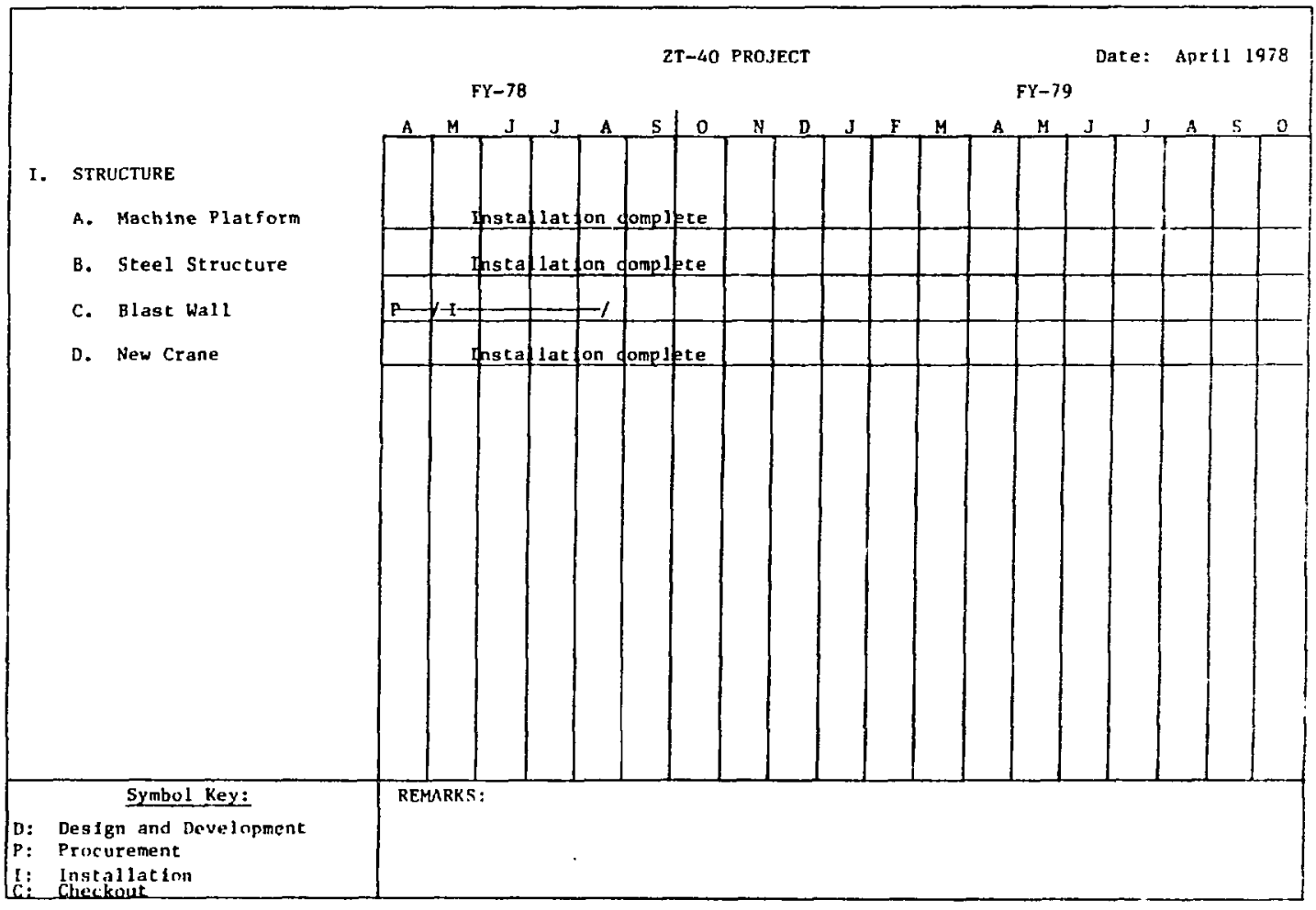



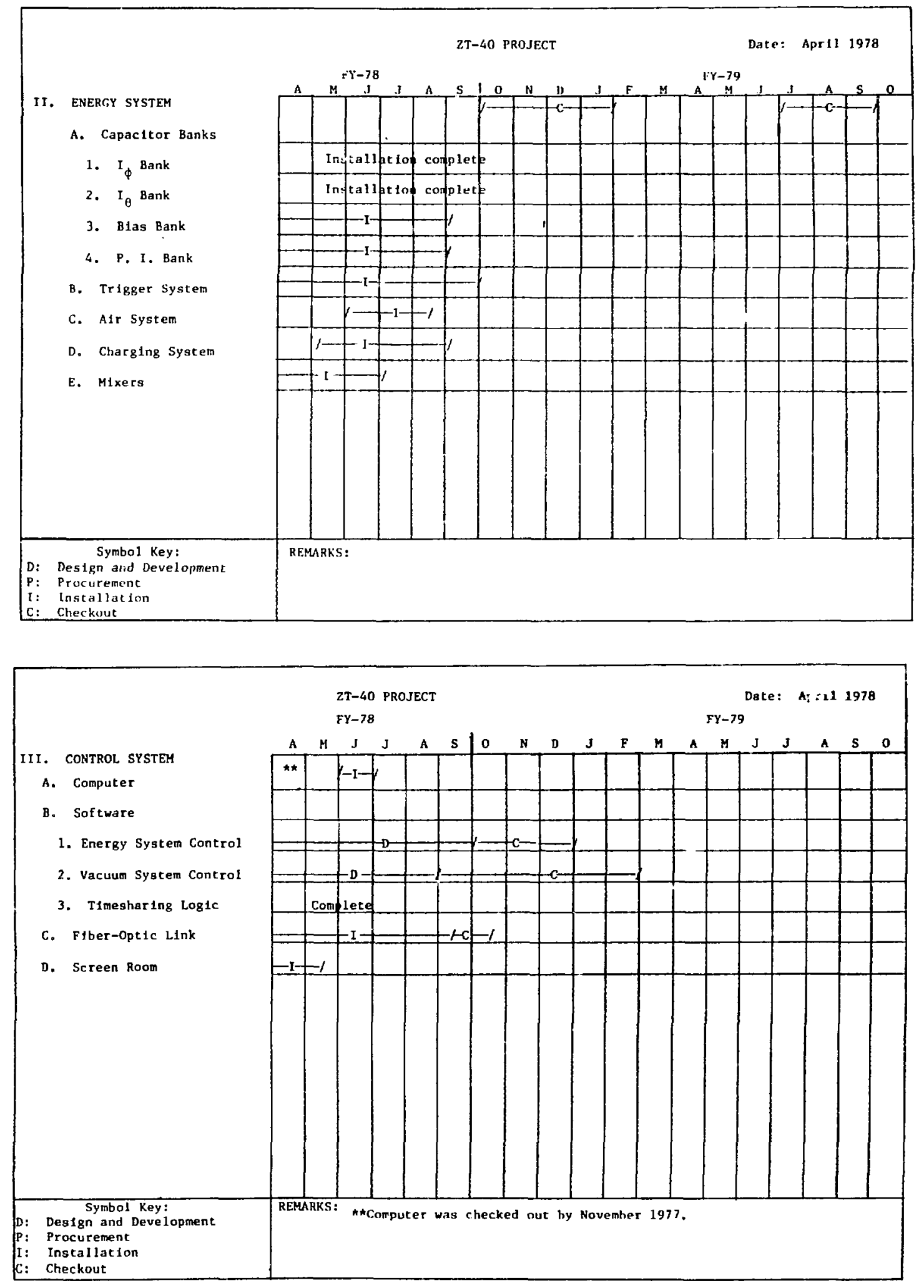

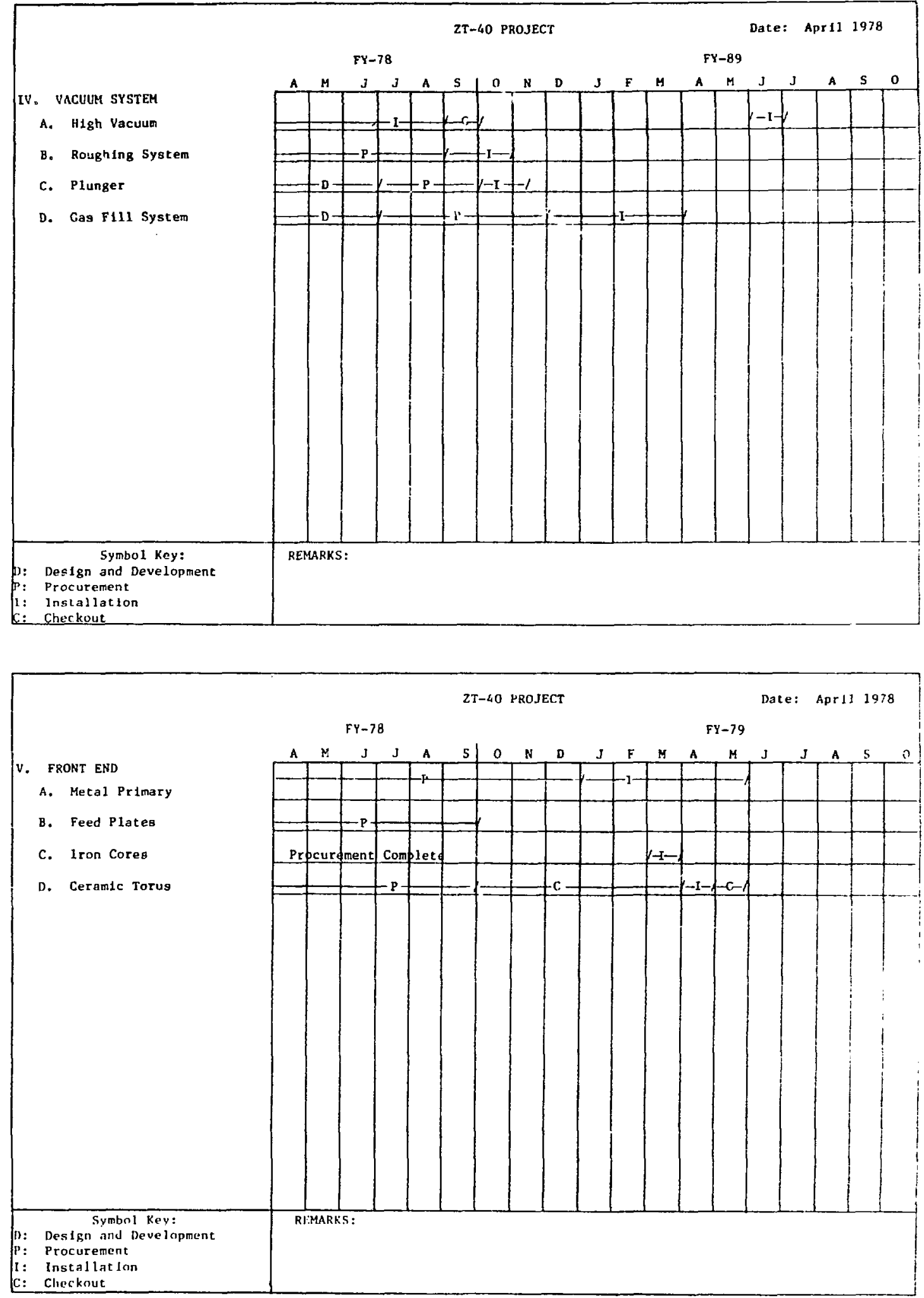


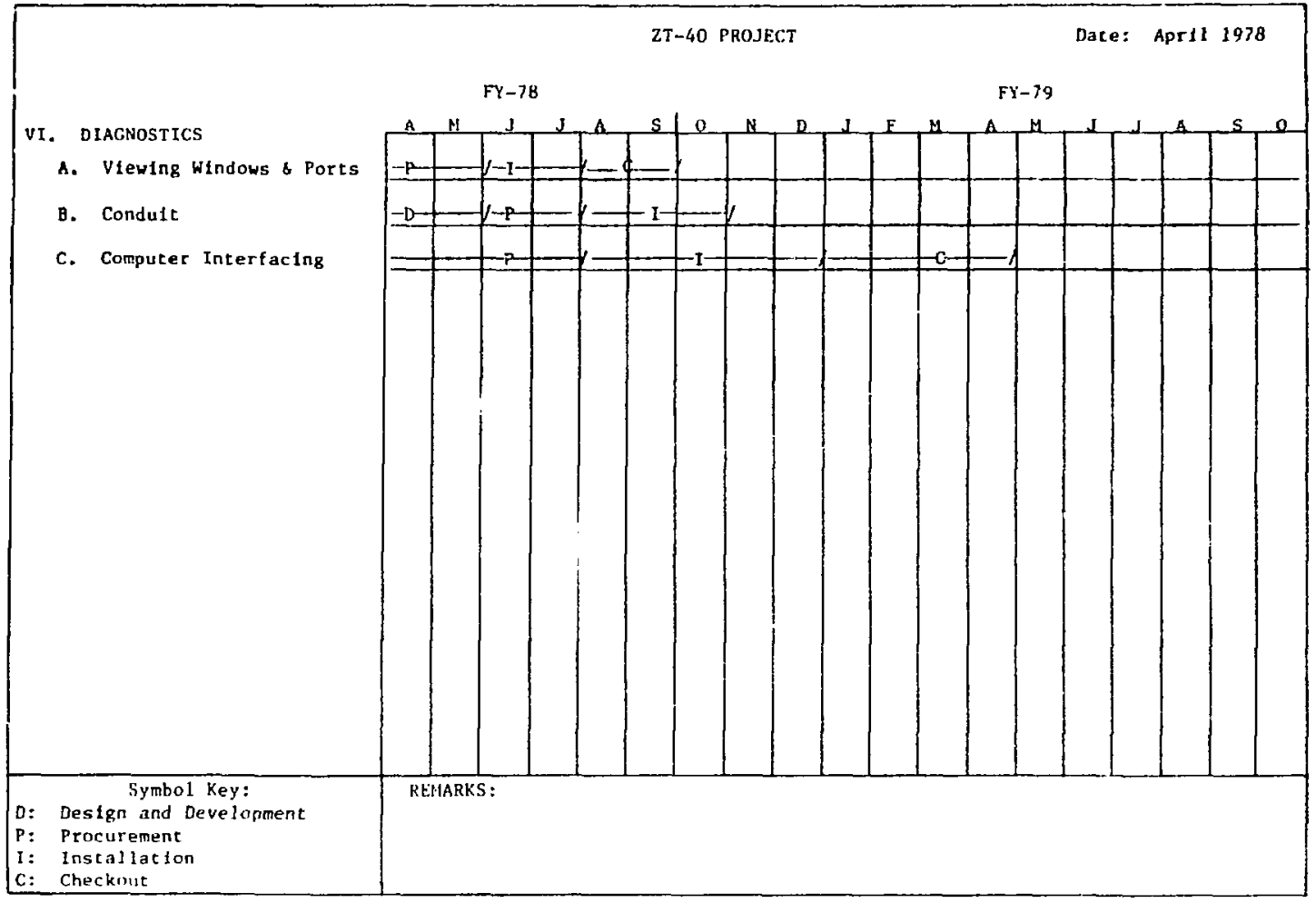

2T-40 PROJECT

Date: April 1978

VII. POWER CROWBAR

A Bank

B. Spark Gapg

C. Coupling Trangformer

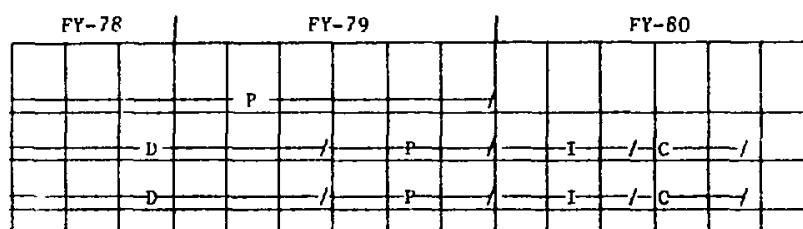

$P$ : Procurement

I: Installation

C: Checkout 